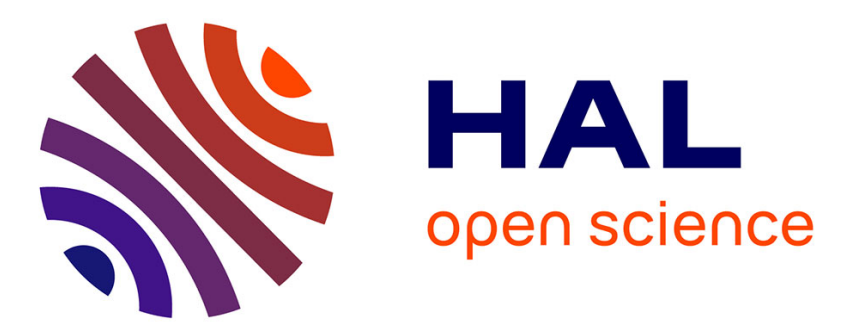

\title{
Spatial and taxonomic correlates of species and species trait assemblages in soil invertebrate communities
}

Jean-François Ponge, Sandrine Salmon

\section{To cite this version:}

Jean-François Ponge, Sandrine Salmon. Spatial and taxonomic correlates of species and species trait assemblages in soil invertebrate communities. Pedobiologia, 2013, 56 (3), pp.129-136. 10.1016/j.pedobi.2013.02.001 . hal-00831698

\section{HAL Id: hal-00831698 \\ https://hal.science/hal-00831698}

Submitted on 7 Jun 2013

HAL is a multi-disciplinary open access archive for the deposit and dissemination of scientific research documents, whether they are published or not. The documents may come from teaching and research institutions in France or abroad, or from public or private research centers.
L'archive ouverte pluridisciplinaire $\mathbf{H A L}$, est destinée au dépôt et à la diffusion de documents scientifiques de niveau recherche, publiés ou non, émanant des établissements d'enseignement et de recherche français ou étrangers, des laboratoires publics ou privés. 


\section{Spatial and taxonomic correlates of species and species trait}

\section{2 assemblages in soil invertebrate communities}

3

4 J.F. Ponge "S. Salmon

5

6 Muséum National d'Histoire Naturelle, CNRS UMR 7179, 4 avenue du Petit-Château, 91800 Brunoy

7 France

8

9 Running title: Spatial and taxonomic patterns of soil animal communities 


\section{Abstract}

2 Whether dispersal limitation and phylogenetic conservatism influence soil species assemblages is still a debated question. We hypothesized that spatial and phylogenetic patterns influence communities in a hump-backed fashion, maximizing their impact at intermediate spatial and phylogenetic distances. Species-environment relationships are blurred by dispersal limitation and restricted habitat choice at long and short spatial distances, respectively (Hypothesis 1). Co-occurrence of species/traits is limited by divergent evolution of species/traits and competitive exclusion at long and short phylogenetic distances, respectively (Hypothesis 2). Springtails were sampled over a wide array of environmental gradients, between-sample distance varying from a few $\mathrm{cm}$ to several $\mathrm{km}$. We compared communities using species composition, habitat features, and geo-localization. We compared species using co-occurrence, habitat preference, traits and phylogeny. Mantel tests allowed discerning which factors contributed the best to species/traits assemblages. Within the studied area, species composition was influenced by habitat more than space. Traits displayed a strong phylogenetic signal, but they contributed less than habitat preferences to species cooccurrence. Species-environment relationships were better displayed within $200 \mathrm{~m}$ distance, supporting Hypothesis 1. Occurrence-habitat preference relationships were better displayed at family level, supporting Hypothesis 2.

Keywords:Collembola, habitat preferences, phylogeny, species traits, spatial distance

\section{Introduction}

A great deal of studies questioned the way species and/or species traits assemble themselves and addressed rules which govern their assembly at both regional and local level (reviewed in Weiher et al. 2011). Metacommunity approaches and concepts (patch dynamics, 
1 species sorting, mass effects, and neutral dynamics) helped to discern processes acting at

2 various spatiotemporal scales (Leibold et al. 2004). At regional level dispersal and emigration/immigration rates have a prominent influence on the composition and species

richness of communities (Erdmann et al. 2012). At local level two broad categories of assembly processes have been proposed: $(i)$ habitat filters that restrict the range of viable strategies according to ecological requirements of species, and (ii) competitive exclusionand niche partitioning that limits the similarity of coexisting species (Cornwell and Ackerly 2009). The balance between 'space'and 'environment' in the assembly rules of communities is thus strongly dependent of the scale used for the study (Belmaker and Jetz 2011).

Phylogenetic biology has allowed refining assembly rules, raising the importance of evolutionary processes such as phylogenetic conservatism and convergence in the assemblage of traits/speciesat community level (Cavender-Bares et al. 2009). Broadly speaking, phylogenetic relationships of species may dictate whether they compete or not, whether they share the same ecological requirementsor not, and thus whether they cohabit or not.

Based on these various paradigms, spatial and phylogenetic correlates of species/trait assemblages have been successfully used to predict changes in species composition along environmental gradients (Lovette and Hochachka 2006), in the course of natural succession (Brändle et al. 2003), and when and where communities are faced to global change (Barnagaud et al. 2011) or anthropic pressure (Ozinga et al. 2009).

Several soil invertebrate studies questioned whether $(i)$ species/environment relationships are influenced by the spatial distribution of habitats, and if yes to which extent (Winkler and Kampichler 2000), (ii) species/environment relationships are revealed at different spatial scales (Terauds et al. 2011), (iii) habitat preferences and traits of co-occurring species are influenced by their taxonomic relationships (Prinzing 2003). Erdmann et al. 
1 (2012) stressed the importance of regional factors, compared to landuse (local) factors in

2 Central European oribatid mite communities, pointing to 'space' having more importance than 'environment'. Ingimarsdóttir et al. (2012) showed that both species sorting (local effects of the environment) and mass effects (regional effects of dispersal limitation) shaped collembolan and oribatid mite communities in nunataks (deglaciated land). Kounda-Kiki et al. (2009) showed that within-thicket (3 m) overwhelmed between-thicket (30 m) variation in soil invertebrate communities on a tropical inselberg, pointing to 'environment' having more influence than 'space'. Lindo and Winchester $(2008,2009)$ embraced in the same study a variety of scales ranging from the 'local' scale, at which most soil organisms interact with their environment, to the 'regional' scale at which land use change mayimpact soil animal communities. The interest of such a multilevel approach, focusing on how organisms perceive landscape units, has been stressed by Chust et al. (2003).

Among soil invertebrates, we selected springtails (Hexapoda, Collembola) as a monophyletic group for which a great deal of work has been devoted to community-level assessment of species/environment relationships (reviewed byRusek1998 andVan Straalen et al. 2008), and for which taxonomy is stable and fairly well supported by molecular investigations(Porco and Deharveng 2009). Van Straalen et al. (2008) showed that these wingless basal hexapods were a good model to test general biological principles. Ponge (1993) showed that a limited number of ecological factors could explain the distribution of Collembola species when collected in the same geographical context. Vertical distribution is the main gradient along which most springtail species are distributed at the 'local' scale(Ponge 2000; Krab et al. 2010), followed by other factors such as water availability (Verhoef and Van Selm 1983), soil acidity (Loranger et al. 2001), and land use (Salmon and Ponge 2012), at 'regional' and intermediate scales. 
In the present study we attempt to discern whether factors of variation other than discernible environmental gradients might exist in the composition of springtail communities.First, we will question the importance of spatial scale in species/environment relationships. We already showed on the same data set that species (Ponge 1993) and traits (Salmon and Ponge 2012)are distributed according to habitat requirements of species. In the present paper, we make substantial additions to this knowledge, pointing to the importance of spatial scale, which was not taken into account so far on this data set. On the base of aforementioned regional versus local influences on species composition we hypothesize thatat 'regional' scale the selection of habitats is limited by dispersal capacities of specieswhile at 'local' scale it is limited by the number of habitats at disposal. As a consequence, species/environment relationships should be better expressedat intermediate scales (Hypothesis 1).

Second, we question the importance of phylogenetic relationships in species/environment and trait/environment relationships. We hypothesize that $(i)$ coexisting species are less phylogenetically distant (and thus share more trait attributes) than segregating species, i.e. display underdispersion(Weiher and Keddy 1995), but also that (ii) at low taxonomic levels the relationship between phylogenetic proximity and co-occurrence is traded-off by competitive exclusion.Thereby, phylogenetic distance will better influence cooccurrenceat not too high and not too low taxonomic levels (Hypothesis 2).

\section{Materials and methods}

Origination of the data

The Sénart forest (Ile-de-France, northern France, $48^{\circ} 40^{\prime}$ N, $2^{\circ} 29^{\prime}$ E) and its vicinity were selected because they display a great variety of soil and soil-related habitats (woodland, heathland, grassland, ponds, paths, tree trunks,...) composing a little more than 3,000 ha of 
1

2

variegated landscape, now totally included in the Paris area. Data collected from 1973 to 1977, at a time when agriculture was still in usage both inside and outside the forest, were revisited for a statistical analysis taking into account spatial and phylogenetic influences on species/environment relationships, still poorly addressed by soil biologists at the time of sampling. The same pool of data (370 samples, 127 species) has been already used in a study on species/environment relationships (Ponge 1993) and was included in the COLTRAIT data base, which also comprises data for twelve morphological and life-history traits of more than 300 Collembola species. The COLTRAIT database is still not implemented on a website but a short presentation is available at [http://www.bdd-inee.cnrs.fr/spip.php?article51\&lang=en] and a research report is available (in French only) at [http://hal.archivesouvertes.fr/docs/00/60/78/37/PDF/Enrichissement_de_la_base_de_donnA_es_COLTRAIT.pd f]. The COLTRAIT database has been used in a previous paper devoted to trait/environment relationships (Salmon and Ponge 2012).

Site description

The Sénart state forest (3,000 ha) is located $20 \mathrm{~km}$ south-east of Paris on the western border of the Brie plateau, delineated by a meander of river Seine and by a tributary, the river Yerres, at an altitude ranging from 50 to $87 \mathrm{~m}$ a.s.l. At the time of sampling it was mainly bordered by urbanized areas (communes of Quincy-sous-Sénart, Boussy-Saint-Antoine, Brunoy, Yerres, Montgeron, Draveil) on its western and northern sides, and by agricultural areas (communes of Soisy, Étiolles, Tigery, Lieusaint, Combs-la-Ville) on its eastern and southern sides. Nowadays, the forest is totally included in the metropolitan area of Paris. Private peripheral woods and agricultural areas (cultures and meadows) were included in the study. Since the time of samplingmost private woods have been incorporated to the state forest, but agricultural areas have been built or transformed into golf courses or other 
1

recreational areas. More details about climate, soils and vegetation are given in Salmon and Ponge (2012).

Looking at historical reviews (Chodron de Courcel 1930) and botanical censuses (Gaume 1938) reveals that before World War II a large part of the western part of the forest, in particular the Uzelles de Draveil ('uzelles' meaning commons in old French) were used for extensive agriculture and were progressively afforested after agriculture abandonment, now subsisting on a small surface in the form of a managed ericaceous heath. As soon as 1938 Gaume indicated that the Rû d'Oly (a brook flowing westward in the western part of the forest) was losing its botanical richness, due to the abandon of pasture in the wet meadows bordering it (Gaume 1938).

Sampling procedure and species identification

Sampling took place from $15^{\text {th }}$ October 1973 to $10^{\text {th }}$ October 1977 in every season and every kind of weather, our purpose at that time being to embrace all climate conditions, except when the soil was deeply frozen and could not be sampled at all. At each sampling occasion, a point was randomly selected on a map and geo-referenced, around which, upon visit, all kinds of habitatsand micro-habitats potentially available to springtails were investigated, from deep soil (leached mineral horizons) to tree trunks two meters aboveground and to floating vegetation in water-filled ponds when present in the vicinity. In average, a circle of ca. $10 \mathrm{~m}$ around the randomly selected point was scrutinized for the variety of habitats, which varied to a great extent according to landuse (from 5 to 15 habitats/microhabitats per sampling plot). By this procedure sampling was done only once in each of the 42 sites thus visited. Distances between samples were classified in seven classes: less than $2 \mathrm{~cm}$ (607 couples), from 2 to $20 \mathrm{~cm}$ (288 couples), from $20 \mathrm{~cm}$ to $2 \mathrm{~m}$ (442 couples), from 2 to 20 m (1,594 couples), from 20 to $200 \mathrm{~m}$ (5,128 couples), from $200 \mathrm{~m}$ to $2 \mathrm{~km}(32,043)$, and from 
12 to $20 \mathrm{~km}(75,118$ couples). Mean sampling interval was 34 days, distributed among the four

2 seasons, summer being somewhat undersampled $(28 \%, 32 \%, 26 \%$ and $14 \%$ of total number of

3 samples in autumn, winter, spring and summer, respectively). No effort was done to

4 standardize sampling, the only requirement being to collect enough animals to get an idea of

5 species distribution in each sample (ca. more than 30 specimens per sample):at that time the

6 aim of the study wasjust to compare samples on the base of species distribution, without any

7 standard requirement for surface or volume. The volume sampled varied from $100 \mathrm{~mL}$ for

8 moss cushions, which are particularly rich in springtails (Gerson 1982)to $1 \mathrm{~L}$ for bleached

9 mineral soil horizons which are strongly impoverished in fauna (Hågvar 1983). The total number of samples was 370, which contained 127 species. Care was taken not to undersample some poorly represented habitats, such as calcareous soilsand dumping places, which necessitated some complementary sampling (48 and 11 samples, respectively). Such a selection procedure, combining random selection of sampling sites and directed choice of habitats and micro-habitats, allows environmental gradients to be more fully described (Gillison and Liswanti 2004).

At the time of study the only key available for European springtails was that of Gisin (1960), to which were added numerous detailed published studies at family, genus or species level (complete list available upon request), and miscellaneous (unpublished) additions by Gisin himself. Gisin's nomenclature was updated using Fauna Europaea 2011 [http://www.faunaeur.org/]. A total of 127 species were found (Appendix 1).

Habitat data

Field notes taken at the time of sampling were used to classify habitat/micro-habitat features in 82 habitat indicators, including seasons and vertical stratification (Appendix 2). To each sample was thus assigned a set of 82 binary variables (coded as 0 or 1 ) which describe 
1 its main features at varying scales, from landscape (heathland, grassland, woodland) to

2 sampling plot (ditch, plain ground, pond, vegetation, soil $\mathrm{pH} .$. ) then to sample scale (plant

3 parts, litter and soil horizons, earthworm casts,...). A zero value for an habitat indicator might

4 mean either that it could not be estimated (for instance $\mathrm{pH}$ does not mean anything for plant

5 aerial parts) or that it was mutually exclusive with another indicator (for instance if sampling

6 was done in autumn, then winter, spring and summer indicators were automatically given the

7 value 0 ). The only meaningful value for the association of a sample witha habitat indicator

8 was thus 1 . In many instances the information given by habitat indicators could beat least

9 partly redundant (viz. limestone and mull) or nested (viz. pond and water), but full redundance was excluded. The same latitude and longitude values (extended Lambert coordinates) were assigned to all samples collected in the vicinity of a pre-designed point.

Phylogeny/taxonomy data

In the absence of a complete phylogeny of Collembola, we used the Checklist of the Collembola of the World [http://www.collembola.org/], which is the most refined and updated taxonomic classification of springtails, incorporating most recent results of molecular and morphological investigations on this monophyletic group of Hexapoda.

Trait data

Twelve traits, mostly extracted from the COLTRAIT data base and collected from numerous identification keys or synopsis, describe the morphology and reproductive mode of the 127 species used in the analysis (Salmon and Ponge 2012). In particular, we selected traits thought to be more responsive to distance and habitat: visual, mechanical and olfactory organs (eyes, trichobothria, post-antennal organs, and antennae) and coloration allow animals to select and/or withstand habitats/micro-habitats according to their physiological requirements, reviewed in Hopkin (1997). More details on selection of traits and trait attributes are given in 
1 Salmon and Ponge (2012). The 30 trait attributes were coded as binary (dummy) variables

2 (Appendix 3).Morphological traits related to the mobility of species (visual and jumping apparatus, length of legs) were used to classify species in putative fast and slow dispersers

4 according to Ponge et al. (2006).

Statistical treatment of the data

Mantel testswere devised to partial out the spatial component of ecological variation (Legendre 1989) and were used successfully in the study of species-environment relationships in microarthropod communities (Borcard and Legendre 1994; Lindo and Winchester 2009). In the present study we extended this method to the study of trait-environment relationships by discarding the effect of phylogenetic variations, as an alternative to the use of phylogenetic contrasts (Martins and Hansen 1997).Partial and simple Mantel tests were used to measure the correlation between distance/dissimilarity matrices, with and without discarding the effect of one of them on the two others, respectively.

Dissimilarities between samples were calculated on the base of species composition, habitat indicators and space.The Spearman coefficient of dissimilarity $D=\left(1-r_{s}\right) / 2, r_{s}$ being the Spearman's rank correlation coefficient, was used as a measure of dissimilarity between samples based on species abundances. The Spearman rank correlation coefficientallowed taking into account the large variation in population size which was observed betweene.g. moss cushions, a micro-habitat which harbors numerous springtails, and mineral soil horizons, a micro-habitat strongly impoverished in these animals. This method based on ranks rather than on pure or transformed data (see Anderson et al. 2006 for a review on similarity indices) allows comparisons based on the whole community composition, whatever the theoretical distributions of species abundances, and decreases the variability due to sample size heterogeneity (Gauthier 2001).Dissimilarities between samples based on habitat 
1 indicators (dummy variables taking 0 or 1 value) were calculated using the Jaccard distance,

2 i.e. one minus the number of habitat indicators shared by a couple of samples divided by the total number of habitat indicators when both samples are pooled. The Jaccard distance varied

4 from 0 (identity) to 1 (complete dissemblance). This measure of habitat dissimilarity was used

5 to calculate an average between-sample habitat dissimilarity at varying scales.

7 a logarithmic scale: $0(<2 \mathrm{~cm}), 1(2-20 \mathrm{~cm}), 2(20 \mathrm{~cm}-2 \mathrm{~m}), 3(2-20 \mathrm{~m}), 4(20-200 \mathrm{~m})$,

$85(200 \mathrm{~m}-2 \mathrm{~km})$ and $6(2-20 \mathrm{~km})$. We calculated a Mantel rank correlation coefficient

9 between habitat and composition at varying spatial scales, i.e. by increasing the distance over which samples were compared. The finest scale used for this calculation was for samples located at less than $2 \mathrm{~m}$ the one from the other, while the largest scale was for the whole set of samples, i.e. less than $20 \mathrm{~km}$.

Dissimilarities between species were calculated on the basis of occurrences

(abundance values in the different samples), traits, habitat preferences and phylogeny. Habitat preferences were cross-calculated by multiplying the matrix of abundance values (127 species x 370 samples) by the matrix of habitat features ( 370 samples x 82 features, coded as 0 or 1 ).

The resulting matrix (127 species x 82 habitat features) was divided by the total abundance of each species, in order to compare them on the base of relative preferences (sum of habitat preferences equal to 1 for each species, whether abundant or not).Dissimilarities between species using occurrenceand habitat preference were calculated using the Spearman dissimilarity coefficient, as explained above.Dissimilarities between species using traits were calculated using the Jaccard distance, as explained above for samples using habitat indicators. 
Taxonomic distances were calculated using as a numerical estimate, the rank level at which taxa were associated: 1 (subspecies), 2 (species), 3 (subgenus), 4 (genus), 5 (tribe), 6 (subfamily), 7 (family), 8 (superfamily), and 9 (order).

In all calculations of dissimilarity/distance matrices between species, whether based on occurrence, traits or taxonomy, rare and common species were given the same weight, in the same manner as species-poor and species-rich samples were given the same weight in between-samples matrices. This is justified by the fact that we do not have a priori reasons for judging that species-rich samples (resp. common species) are more informative than speciespoor samples (resp. rare species).

Species accumulation curves were calculated to estimate the exhaustiveness of our sampling method and to compare different geographical areas within the Sénart forest. In particular we arbitrarily divided the Sénart forest (ca. 8 x $8 \mathrm{~km}$ ) in a western and an eastern part, each of them ca. $4 \times 8 \mathrm{~km}$, on the base of aforementioned suspected differences in past landuse. The same method was also applied to a comparison of the number of environmental indicators (habitat features) between both geographical areas.Species accumulation curves and jacknife estimators were calculated using EstimateS (version 8.2.0). Each sample was considered a unit, containing a number of specimens belonging to different species. A cumulative curve displays the increase in number of species when the number of samples increases, on the base of observed means. Confidence intervals around observed means were calculated according to the Mao Tau model (Colwell et al. 2004). The number of missing species was estimated according to Chao (1987). Comparisons between accumulation curves were performed by Chi-square tests.

Fisher's exact test was used to compare the distribution of fast- and slow-dispersers (present vs. absent) between western and eastern parts of the Sénart forest and to compare the 

5 (Addinsoft $^{\circledR}$, Paris, France).

number of habitats (present vs. absent) between both areas.Sign test was used to compare the distribution of species habitat preferences (explained above) between western and eastern parts of the Sénart forest (only species common to both areas were taken into account).

All calculations (to the exception of accumulation curves) were done using XLSTAT $^{\circledR}$

\section{Results}

The spatial component of species-environment relationships

The accumulation curve of the 127 observed species over the 370 samples (Fig. 1a) showed that sampling had approached an asymptote, indicating that sampling effort was adequate to embrace collembolan biodiversity of the Sénart forest. The expected total number of species was 133 or 137 according to Chao 1 and Chao2 estimators. Accumulation curves for the western and eastern parts of the Sénart forest differed to a significant extent: for the same sampling effort there was a lesser number of species in the western part of the forest (Fig. 1b).

Mantel tests (Table 1) indicated that dissimilarities between samples according to species composition and according to habitat indicators were positively correlated: the more dissimilar were habitat indicators, the more dissimilar Collembola communities were in their species composition. Although highly significant in both cases, this relationship was better expressed when the effect of spatial distance was discarded, resulting in a higher Mantel statistic. There was a positive and highly significant relationship between spatial distance and compositional dissimilarity of samples, although this correlation was poorer than that between composition and habitat: the more spatially distant were the samples, the more distinct they were in their species composition. This correlation was much lesser although still highly significant when the effect of habitat was discarded. At last, habitat dissimilarity and spatialdistance were positively and highly significantly correlated, the value of the Mantel 
statistic (0.38) being higher than between space and species composition (0.17) but near equal to that between habitat and species composition (0.36): the more spatially distant the samples, the more they differed in habitat features. The positive correlation between habitat dissimilarity and spatial distance explains why the positive correlation between compositional and habitat dissimilarities increased when spatial effects were discarded: this correlation was better expressed at short distance.

Taking the value of the Mantel statistic as a measure of species-environment relationships over the range of studied spatial scales (Fig. 2a) it can be seen that a maximum value was obtained at the $200 \mathrm{~m}$ scale (0.49), which was not far from the value obtained when spatial effects were excluded from the total set of samples (0.55). At larger and finer scales, $r_{M}$ values were lower and became not significant below $20 \mathrm{~m}$. This indicated that speciesenvironment relationshipswere blurred at distances higher than $200 \mathrm{~m}$ or shorter than $20 \mathrm{~m}$. The poor explanatory value of habitat features for more neighboring samples $\left(\mathrm{r}_{M}\right.$ values not significant at distances $<20 \mathrm{~m}$ ) can be explained by a lack of variety of the environment at short distance. This was verified by the average habitat dissimilarity between samples (calculated on the base of between-sample dissimilarity of habitat indicators), which sharply increased with scale amplitude (Fig. 2b): the larger the scale, the larger the variety of habitatssampled.

Environmental variety cannot explain the abovementioned higher number of species inthe eastern part of the forest, as exemplified by accumulation curves of habitat indicators, which did not differ between western and eastern parts of the forest (Fig. 1b).Accordingly, habitat preferences of the 77 species common to both parts of the forest did not reveal any difference between western and eastern parts (sign test, $\mathrm{P}=0.96$ ). The deficit in species richness observed in the western part of the forest (27 species, minus $23 \%$ ) was significant (Fisher's exact test, $\mathrm{P}<0.0001$ ), and could not be explained either by a deficit in habitats 
1 (Fisher's exact test, $\mathrm{P}=0.84$ ) or by unbalanced sampling effort (Fig. 3). A distinction

2 between slow vs fast dispersers (Fig. 4) showed that the balance between slow and fast dispersers (ca. 76\% in favor of slow dispersers in the eastern part of the forest) shifted to $50 \%$ for species common to both parts of the forest or for species living only in the western part.

The taxonomic component of traits, habitat preference and species co-occurrence

Using taxonomic distances as a proxy to phylogenetic distances (Table 2), Mantel testsshowed, apart from the trivial result that traitsand taxonomy were correlated, thattrait and habitat preference dissimilarities were positively and highly significantly correlated, evenwhen excluding taxonomy. The relationship between habitat preference dissimilarity and taxonomic distance was also positive and significant, but significance vanished when traits were excluded, pointing to traits mediating the observed effect of taxonomy on habitat preference.

Other Mantel tests showed that species occurrence dissimilarity was positively and significantly explained by habitat preference $\left(r_{M}=0.48\right)$ and, although to a lesser extent, by traits $\left(r_{M}=0.12\right)$ and taxonomy $\left(r_{M}=0.07\right)$ : species which occurred together in the same samples exhibited similar habitat preferences and traits, and they were closely related from a taxonomic point of view (Table 3). The use of partial Mantel tests, allowing discarding the effect of one of these three factors, did not show major increases or decreases of these values, to the exception of the relationship between occurrence dissimilarity and taxonomy: this positive relationship totally disappeared when the influence of traits was discarded (partial $r_{M}$ $=-0.001, P=0.97)$ while it remained near unchanged when habitat preference effects were discarded (partial $\mathrm{r}_{\mathrm{M}}=0.05, \mathrm{P}<0.0001$ ), pointing to traits as the major component of the influence of taxonomy on species occurrence dissimilarity. 
We used Mantel tests between species occurrence and habitat preference dissimilarity matrices at successive taxonomic levels to question whether the positive relationship between occurrence and habitat preference dissimilarities (Table 3) varied according to taxonomic level. Figure 5 showed that the Mantel statistic measuring the correlation between occurrence and habitat preference dissimilarities displayed a humped-back pattern. The maximum value was observed at family level, and decreased to non-significant values at genus and species levels: species with similar habitat preferences had more opportunities to live together when they belonged to the same family, this relationship being blurred to some extent at higherorder taxonomic levels and disappearing totally (although being still positive) at genus and species levels.

We wondered whether species taxonomically close and with similar habitat preferences were dissimilar from the point of view of occurrence, as expected from competitive exclusion. This was not supported by our results on couples of species belonging to the same genus (Fig. 6): except for the couple Folsomia manolacheiXFolsomia quadrioculata couples of species with a high similarity in habitat preference exhibited a positive, neutral or weakly negative occurrence similarity.

\section{Discussion}

Within the studied area, we showed that species composition was more influenced by habitat than by space. However, we also showed that when samples to be compared were separated by a distance shorter than $20 \mathrm{~m}$ or higher than $200 \mathrm{~m}$, the explanatory value of habitat indicatorsfor species occurrence decreased, pointing to variation in the composition of springtail communities which is not entirely explained by habitat selection at short and long spatial distances, thereby supporting Hypothesis 1 . 
The western part of the Sénart forest was impoverished in species, in particular in species with poor dispersal ability, which can be explained by recent (100-50 years) tree encroachment in previous agricultural land. This is reminiscent of a study done in another region by Ponge et al. (2006), showing that there was a deficit in species with poor-dispersal capacity (corresponding to subterranean life) in areas where woody coverage changed abruptly in the course of the last half century. Can we expect the occurrence of a similar phenomenon in the studied forest? And did it correspond to the observed east-west gradient of decreasing biodiversity, despite similar richness in habitats? The observed discrepancy between both parts of the forest in the balance between slow and fast dispersers led us to suspect some delay in the dispersal of slow-moving species when colonizing forested environments issued from previous agricultural land. Such a delay in colonization success at regional scale, resulting in a loss of biodiversity at local scale, has been coined mass effect in the frame of metacommunity theory (Guélat et al. 2008), and colonization credit in the frame of restoration science (Cristofoli et al. 2010).

Decrease in the explanatory value of habitat indicators for species co-occurrence observed at short distance $(<20 \mathrm{~m})$, expressed bynon-significant Mantel correlation coefficients between habitat and species occurrence dissimilarities, was ascribed to a restricted array of habitats available for habitat selection, making species sorting (environmental filters) not fully expressedat fine scale. This phenomenon is related to the more general problem of nichewidth in motile organisms: the more habitats will be visited by an animal, the more its choice will fit its requirements, resulting in a better match between ecological traits and environmental characteristics (Edelaar et al. 2008).

In the present study we showed that taxonomically distant springtail species $(i)$ were more dissimilar in their anatomical and reproductive traits, which is expected since some of these traits are used to classify them by systematicians, but also(ii) tended to be spatially 
segregated despite of the fact that habitat preference was the main determinant of species occurrence. The weaker but significant and positive correlation between taxonomic distance and occurrence dissimilarity (phylogenetic clustering sensu Cavender-Bares et al. 2004) did not vary to a great extent when habitat preferences were discarded but near totally disappeared when traits were excluded, indicating that phylogenetic correlates of species assemblages were mediated by traits. This is supported by the disappearance of the correlation observed between taxonomic distance and habitat preference dissimilarity when traits were excluded, pointing to phylogenetic conservatism of species traits and to environmental filtering of species through their traits (Cavender-Bares et al. 2009).

We showed that the positive relationship between occurrence and habitat preference (species exhibiting similar habitat preferences tend to co-occur more than random) was taxonomically sensitive. It was better expressed at the family level, and was no longer significant (although still positive) at genus and species levels, supportingHypothesis 2. Environmental/physiological filtering or species sorting (occurrence explained by habitat preference) culminates at family level, which might indicate that assembly rules based on habitat preferences (species having similar habitat preferences tend to assemble) are blurred by biological filtering (competitive exclusion) when species are closely related, and are blurred (although to a weak extent) by convergent evolution and co-adaptation at higher taxonomic levels. That closely related species tend to segregate because of competitive exclusion (Cavender-Bares et al. 2004, but see Guélat et al. 2008) was not supported by our results, except on one couple of congeneric species, but we cannot exclude that competition might decrease species coexistence to some extent. Most congeneric species exhibited a positive occurrence similarity and only the couple Folsomia quadrioculataxF. manolachei was spatially segregated (i.e. exhibited a negative occurrence similarity) while displaying 
1 similar habitat preferences. All these results point to a phylogenetic signal in species co-

2 occurrence, traded-off by competition at low taxonomic levels (Helmus et al. 2007).

Overall, habitat indicators (for samples) and habitat preferences (for species) were two main determinants of the composition of Collembola communities, with a small, although significant contribution of spatial and phylogenetic variation, the latter being mediated by species traits. The small influence of dispersal limitation on the composition of soil arthropod communities, compared to environmental variability, has been already observed on naked granite, where isolation between patches of variegated vegetation was near total and withinpatch variation was much higher than between-patch variation (Kounda-Kiki et al. 2009). This property is shared by microbial communities, where Beijerinck's 'everything is everywhere, but, the environment selects' is a still widely respected adage at world scale (Queloz et al. 2011). However, soil animal groups with poorer dispersal distances than springtails, such as oribatid mites (Åström and Bengtsson 2011), displays a prominent part of species composition which is explained by dispersal limitation (Lindo and Winchester 2008, 2009).

The small influence of phylogenetic variation on species co-occurrence must be compared with that of traits: both contribute to a low, although significant extent,to habitat preference. This might indicate that either $(i)$ other traits than those here considered must be taken into account, or (ii) only a minor fraction of studied traits is involved in the observed effects, or (iii) other factors than traits might influence the composition of soil springtail communities, as suggested by Terauds et al. (2011). The fact that the better explanatory value of habitat features for species composition takes place when samples are located between 20 $\mathrm{m}$ and $200 \mathrm{~m}$ might be explained by species moving around and then deciding to stay and reproduce in better suited (or less worse) habitats (local metacommunity scale sensu Terauds 
1 et al. 2011; regional scale sensu Winkler and Kampichler 2000), i.e. at a distancewhere

2 species poorly interact between them but are filtered by the environment.

\section{References}

Anderson, M.J., Ellingsen, K.E., McArdle, B.H., 2006. Multivariate dispersion as a measure of beta diversity. Ecol. Lett. 9, 683-693.

Åström, J., Bengtsson, J., 2011. Patch size matters more than dispersal distance in a mainlandisland metacommunity. Oecologia 167, 747-757.

Barnagaud, J.Y., Devictor, V., Jiguet, F., Archaux, F., 2011.When species become generalists: on-going large-scale changes in bird habitat specialization.Glob. Ecol.Biogeog. 20, 630-640.

Belmaker, J., Jetz, W., 2011. Cross-scale variation in speciesrichness-environment associations.Glob. Ecol.Biogeog. 20, 464-474.

Borcard, D., Legendre, P., 1994. Environmental control and spatial structure in ecological communities: an example using oribatid mites (Acari, Oribatei). Environ. Ecol. Stat. 1, 37-61.

Brändle, M., Durka, W., Krug, H., Brandl, R., 2003. The assembly of local communities: plants and birds in non-reclaimed mining sites. Ecography, 26, 652-660.

Cavender-Bares, J., Ackerly, D.D., Baum, D.A., Bazzaz, F.A., 2004.Phylogenetic overdispersion in Floridian oak communities. Am. Nat. 163, 823-843.

Cavender-Bares, J., Kozak, K.H., Fine, P.V.A., Kembel, S.W., 2009.The merging of community ecology and phylogenetic biology. Ecol. Lett. 12, 693-715. 
1 Chao, A., 1987.Estimating the population size for capture-recapture data with unequal catchability.Biometrics 43, 783-791.

3 Chodron de Courcel, R., 1930.La Forêt de Sénart: Étude Historique. Champion, Paris.

4 Chust, G., Pretus, J.L., Ducrot, D., Bedòs, A., Deharveng, L., 2003.Identification of landscape units from an insect perspective.Ecography 26, 257-268.

Colwell,R.K., Mao,C.X., Chang, J., 2004. Interpolating, extrapolating, and comparing incidence-based species accumulation curves. Ecology 85, 2717-2727.

Cornwell, W.K., Ackerly, D.D., 2009. Community assembly and shifts in plant trait distributions across an environmental gradient in coastal California. Ecol.Monogr. 79, 109-126.

Cristofoli, S., Piqueray, J., Dufrêne, M., Bizoux, J.P., Mahy, G., 2010.Colonization credit in restored wet heathlands.Restor. Ecol. 18, 645-655.

Edelaar, P., Siepelski, A.M., Clobert, J., 2008. Matching habitat choice causes directed gene flow: a neglected dimension in evolution and ecology. Evolution 62, 2462-2472.

Erdmann, G., Scheu, S., Maraun, M., 2012.Regional factors rather than forest type drive the community structure of soil living oribatid mites (Acari, Oribatida). Exp. Appl.

Gaume, R., 1938. Note sur la flore de la forêt de Sénart (S.-et-O.). Bull. Soc.Sci. Seine-etOise6, 92-97.

Gauthier, T.D., 2001.Detecting trends usingSpearman'srankcorrelation coefficient. Environ.Forensics 2, 359-362. 
1 Gerson, U., 1982.Bryophytes and invertebrates. In:Smith, A.J.E.(Ed.),Bryophyte Ecology. Chapman and Hall, London, pp. 291-332.

Gillison, A.N., Liswanti,N., 2004.Assessing biodiversity at landscape level in northern Thailand and Sumatra (Indonesia): the importance of environmental context.Agr.Ecosyst. Environ.104, 75-86.

Gisin, H., 1960.CollembolenfaunaEuropas. Muséum d'Histoire Naturelle, Geneva.

Guélat, J., Jaquiéry, J., Berset-Brändli, L., Pellegrini, E., Moresi, R., Broquet, T., Hirzel, A.H., Perrin, N., 2008. Mass effects mediate coexistence in competing shrews. Ecology 89, 2033-2042.

Hågvar, S., 1983.Collembola in Norwegian coniferous forest soils. II. Vertical distribution. Pedobiologia 25, 383-401.

Helmus, M.R., Savage, K., Diebel, M.W., Maxted, J.T., Ives, A.R., 2007. Separating the determinants of phylogenetic community structure. Ecol. Lett. 10, 917-925.

Hopkin, S.P., 1997.Biology of the Springtails (Insecta: Collembola). Oxford University Press, Oxford.

Ingimarsdóttir, M., Caruso, T., Ripa, J., Magnúsdóttir, Ó.B., Migliorini, M., Hedlund, K., 2012. Primary assembly of soil communities: disentangling the effect of dispersal and local environment. Oecologia 170, 745-754.

Kounda-Kiki, C., Celini, L., Ponge, J.F., Mora, P., Sarthou, C., 2009.Nested variation of soil arthropod communities in isolated patches of vegetation on a rocky outcrop.Soil Biol.Biochem. 41, 323-329. 
1 Krab, E.J., Oorsprong, H., Berg, M.,Cornelissen, J.H.C., 2010.Turning northern peatlands upside down: disentangling microclimate and substrate quality effects on vertical distribution of Collembola.Funct. Ecol. 24, 1362-1369.

Legendre, P., 1989.Spatial pattern and ecological analysis.Vegetatio 80, 107-138.

Leibold, M.A., Holyoak, M., Mouquet, N., Amarasekare, P., Chase, J.M., Hoopes, M.F., Holt, R.D., Shurin, J.B., Law, R., Tilman, D., Loreau, M., Gonzalez, A., 2004. The metacommunity concept: a framework for multi-scale community ecology. Ecol. Lett. 7, 601-613.

Lindo, Z., Winchester, N.N., 2008. Scale dependent diversity patterns in arboreal and terrestrial oribatid mite (Acari: Oribatida) communities. Ecography 31, 53-60.

Lindo, Z., Winchester, N.N.,2009.Spatial and environmental factors contributing to patterns in arboreal and terrestrial oribatid mite diversity across spatial scales.Oecologia 160, $817-825$.

Loranger,G., Bandyopadhyaya, I., Razaka, B., Ponge, J.F., 2001 Does soil acidity explain altitudinal sequences in collembolan communities? Soil Biol.Biochem. 33, 381-393.

Lovette, I.J., Hochachka, W.M., 2006.Simultaneous effects of phylogenetic niche conservatism and competition on avian community structure.Ecology 87, S14-S28.

Martins, E.P., Hansen, T.F., 1997. Phylogenies and the comparative method: a general approach to incorporating phylogenetic information into the analysis of interspecific data. Am. Nat. 1469, 646-667.

Ozinga, W.A., Römermann, C., Bekker, R.M., Prinzing, A., Tamis, W.L.M., Schaminée, J.H.J., Hennekens, S.M., Thompson, K., Poschlod, P., Kleyer, M., Bakker, J.P.,Van 
Groenendael, J.M., 2009.Dispersal failure contributes to plant losses in NW Europe. Ecol.Lett. 12, 66-74.

Ponge, J.F., 1993.Biocenoses of Collembola in atlantic temperate grass-woodland ecosystems. Pedobiologia 37, 223-244.

Ponge, J.F., 2000.Vertical distribution of Collembola (Hexapoda) and their food resources in organic horizons of beech forests.Biol.Fertil.Soils 32, 508-522.

Ponge, J.F., Dubs, F., Gillet, S., Sousa, J.P., Lavelle, P., 2006.Decreased biodiversity in soil springtail communities: the importance of dispersal and landuse history in heterogeneous landscapes. Soil Biol.Biochem. 38, 1158-1161.

Porco, D., Deharveng, L., 2009. Phylogeny of Collembola based on cuticular compounds: inherent usefulness and limitation of a character type. Naturwiss.96, 943-954.

Prinzing, A., 2003. Are generalists pressed for time? An interspecific test of the time-limited disperser model. Ecology 84, 1744-1755.

Queloz, V., Sieber, T.N., Holdenrieder, O., McDonald, B.A., Grünig, C.R., 2011. No biogeographical pattern for a root-associated fungal species complex. Glob. Ecol.Biogeogr. 20, 160-169.

Rusek, J., 1998.Biodiversity of Collembola and their functional role in the ecosystem.Biodiv.Conserv. 7, 1207-1219.

Salmon, S., Ponge, J.F., 2012. Species traits and habitats in springtail communities: a regional scale study. Pedobiologia 55, 295-301.

Terauds, A., Chown, S.L., Bergstrom, D.M., 2011. Spatial scale and species identity influence the indigenous-alien diversity relationship in springtails. Ecology 92, 1436-1447. 
1 Van Straalen, N.M., Timmermans, M.J.T.N., Roelofs, D., Berg, M.P., 2008.Apterygota in the spotlights of ecology, evolution and genomics.Eur. J. Soil Biol., 44, 452-457.

5 Weiher, E., Keddy,P.A., 1995 Assembly rules, null models, and trait dispersion: new 6

7 Weiher, E., Freund, D., Bunton, T., Stefanski, A., Lee, T., Bentivenga, S., 2011.Advances, 8

Verhoef, H.A., Van Selm, A.J., 1983.Distribution and population dynamics of Collembola in relation to soil moisture.Hol. Ecol. 6, 387-394. questions from old patterns. Oikos 74, 159-164. challenges and a developing synthesis of ecological community assembly theory.Phil. Trans. R. Soc. London B 366, 2403-2413.

Winkler, H., Kampichler, C., 2000. Local and regional species richness in communities of surface-dwelling grassland Collembola: indication of species saturation. Ecography $23,385-392$. 


\section{Figure legends}

Figure 1.Accumulation curves of collembolan species collected in the Sénart forest and in nearby agricultural areas from 1973 to 1977 , with $95 \%$ confidence interval around observed means according to Mao Tau model: (a) whole forest, (b) western and eastern parts of the Sénart forest.

Figure 2. (a) Mantel rank correlation coefficients between compositional and habitat indicator dissimilarity matrices between samples, with or without spatial distance as co-variable, at increasing sampling spatial scales (five maximum spatial distances in a geometric series); (b) Average habitat dissimilarity between samples at increasing sampling spatial scales. N.S. $=$ not significant at 0.05 level. $* * * *=$ significant at 0.0001 level.

Figure 3. Accumulation curves of habitat indicators in Sénart East and Sénart West, with $95 \%$ confidence intervals.

Figure 4. Distribution of fast dispersal and slow dispersal traits within three categories of springtail species: species common to western and eastern parts of the Sénart forest, species only found in the western part and species found only in the eastern part.

Figure 5.Mantel rank correlation coefficients between occurrence and habitat preference dissimilarity matrices between springtail species, at increasing taxonomic levels (from species to order). N.S. $=$ not significant at 0.05 level. $*=$ significant at 0.05 level. $* * * *$ $=$ significant at 0.0001 level .

Figure 6.Relationship between habitat preference and occurrence similarity among springtail species belonging to the same genus. 
Table 1. Results of simple and partial Mantel tests using distance/dissimilarity matrices between samples based on species composition, habitat indicators and spatial localisation. Significant values in bold type (significance level $=0.008$ after Bonferroni correction)

Mantel statistic Probability

\begin{tabular}{lll}
\hline Composition x habitat & $\mathbf{0 . 3 6 0}$ & $<0.0001$ \\
Composition x habitat, space excluded & $\mathbf{0 . 5 4 8}$ & $<0.0001$ \\
& & \\
Composition x space & $\mathbf{0 . 1 7 2}$ & $<0.0001$ \\
Composition x space, habitat excluded & $\mathbf{0 . 0 4 0}$ & $<0.0001$ \\
& & \\
Habitat x space & $\mathbf{0 . 3 7 6}$ & $<0.0001$ \\
Habitat x space, composition excluded & $\mathbf{0 . 3 4 2}$ & $<0.0001$ \\
\hline
\end{tabular}


Table 2. Results of simple and partial Mantel tests using distance/dissimilarity matrices between species based on traits, habitat preference and taxonomy. Significant values in bold type (significance level $=0.008$ after Bonferroni correction)

\begin{tabular}{lll}
\hline & Mantel statistic & Probability \\
\hline Traits x taxonomy & $\mathbf{0 . 5 6 3}$ & $<0.0001$ \\
Traits x taxonomy, habitat preference excluded & $\mathbf{0 . 5 6 1}$ & $<0.0001$ \\
& & \\
Traits $\times$ habitat preference & $\mathbf{0 . 0 6 8}$ & $<0.0001$ \\
Traits x habitat preference, taxonomy excluded & $\mathbf{0 . 0 4 9}$ & $<0.0001$ \\
& & \\
Habitat preference x taxonomy & $\mathbf{0 . 0 4 9}$ & 0.001 \\
Habitat preference $\mathrm{x}$ taxonomy, traits excluded & 0.013 & 0.23 \\
\hline
\end{tabular}


Table 3. Results of simple and partial Mantel tests using distance/dissimilarity matrices between species based on occurrence, compared with habitat preference, traits and taxonomy. Significant values in bold type (significance level $=0.005$ after Bonferroni correction)

Mantel statistic Probability

Occurrence $\mathrm{x}$ habitat preference

0.476

Occurrence $x$ habitat preference, traits excluded

$0.472<0.0001$

Occurrence $\mathrm{x}$ habitat preference, taxonomy excluded

$\mathbf{0 . 4 7 4}<0.0001$

Occurrence $x$ traits

$0.122<0.0001$

Occurrence $x$ traits, habitat preference excluded

$0.101<0.0001$

Occurrence $x$ traits, taxonomy excluded

$0.101<0.0001$

Occurrence $x$ taxonomy

$0.068<0.0001$

Occurrence $x$ taxonomy, traits excluded

$-0.001$

0.97

1

Occurrence $\mathrm{x}$ taxonomy, habitat preference excluded

0.051

$<0.0001$ 

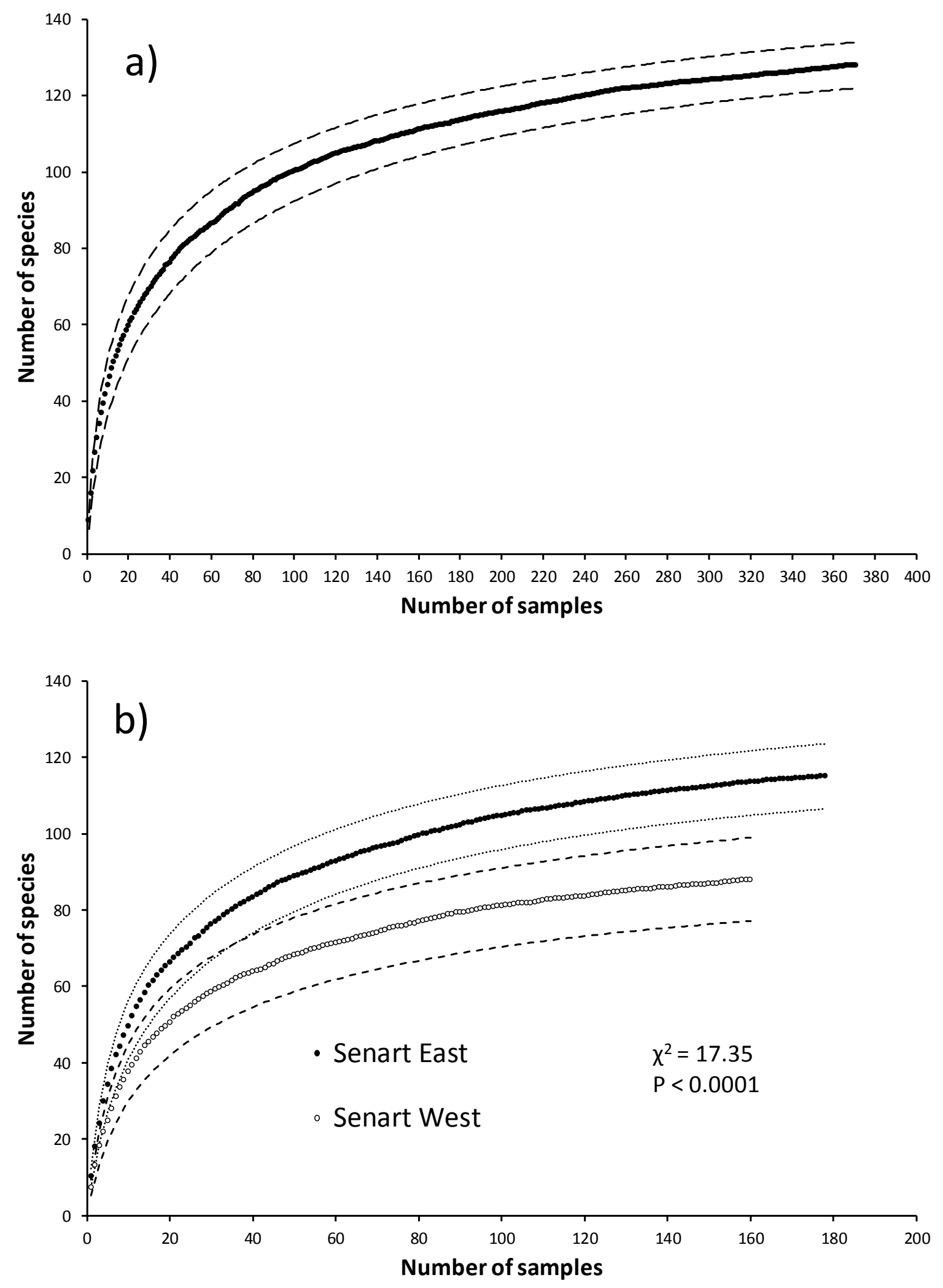

2 Fig. 1 

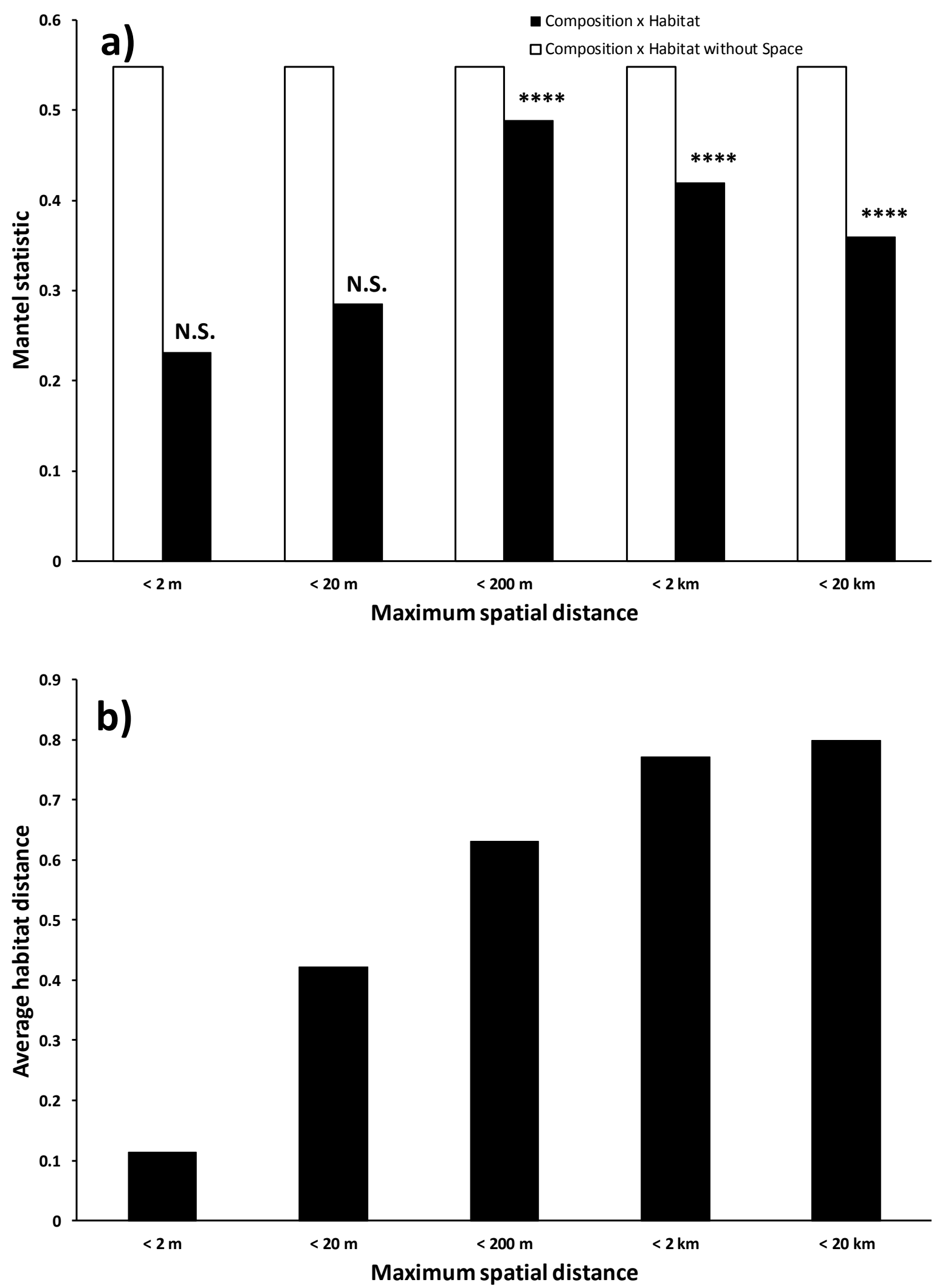

Fig. 2 


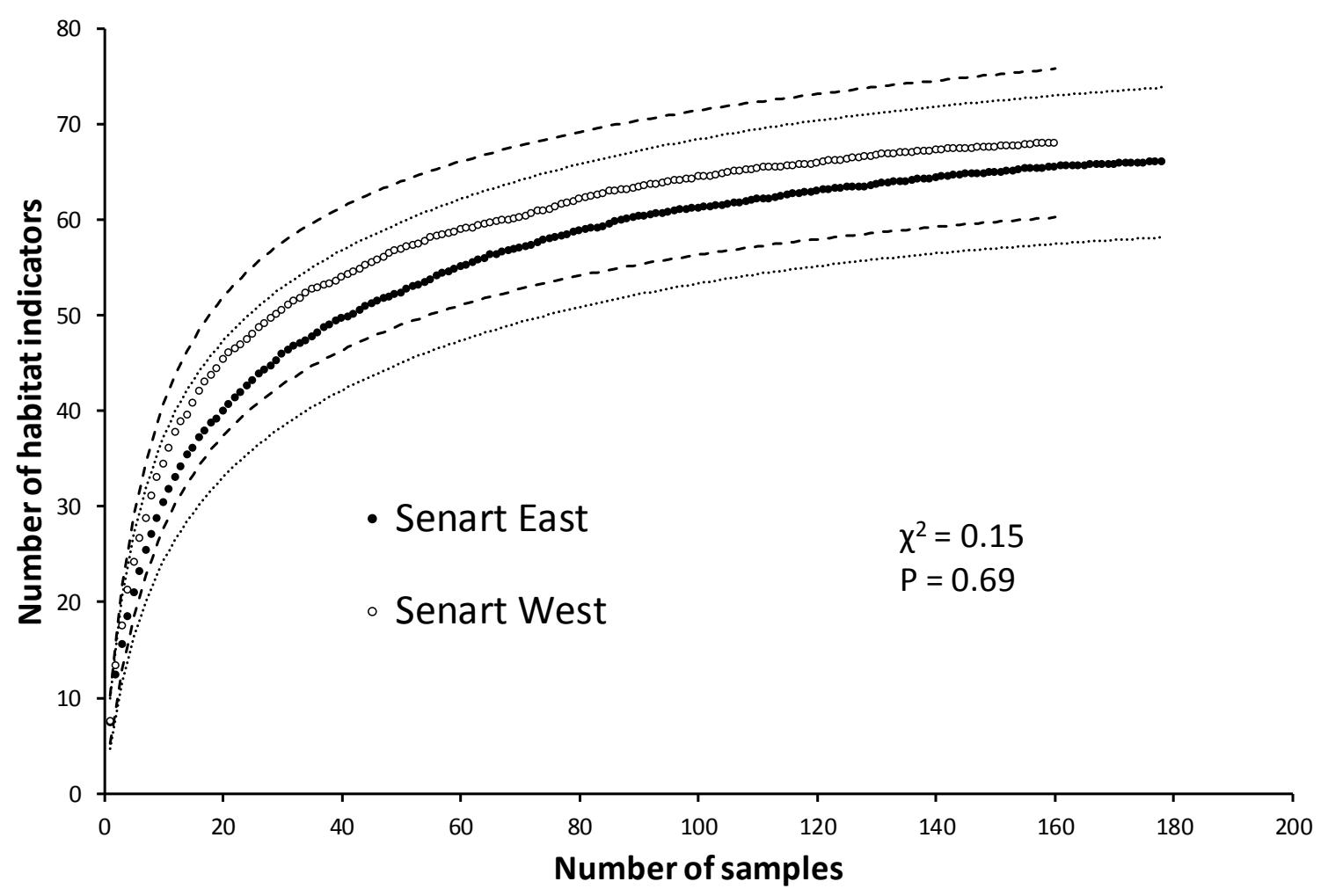

1

2 Fig. 3 


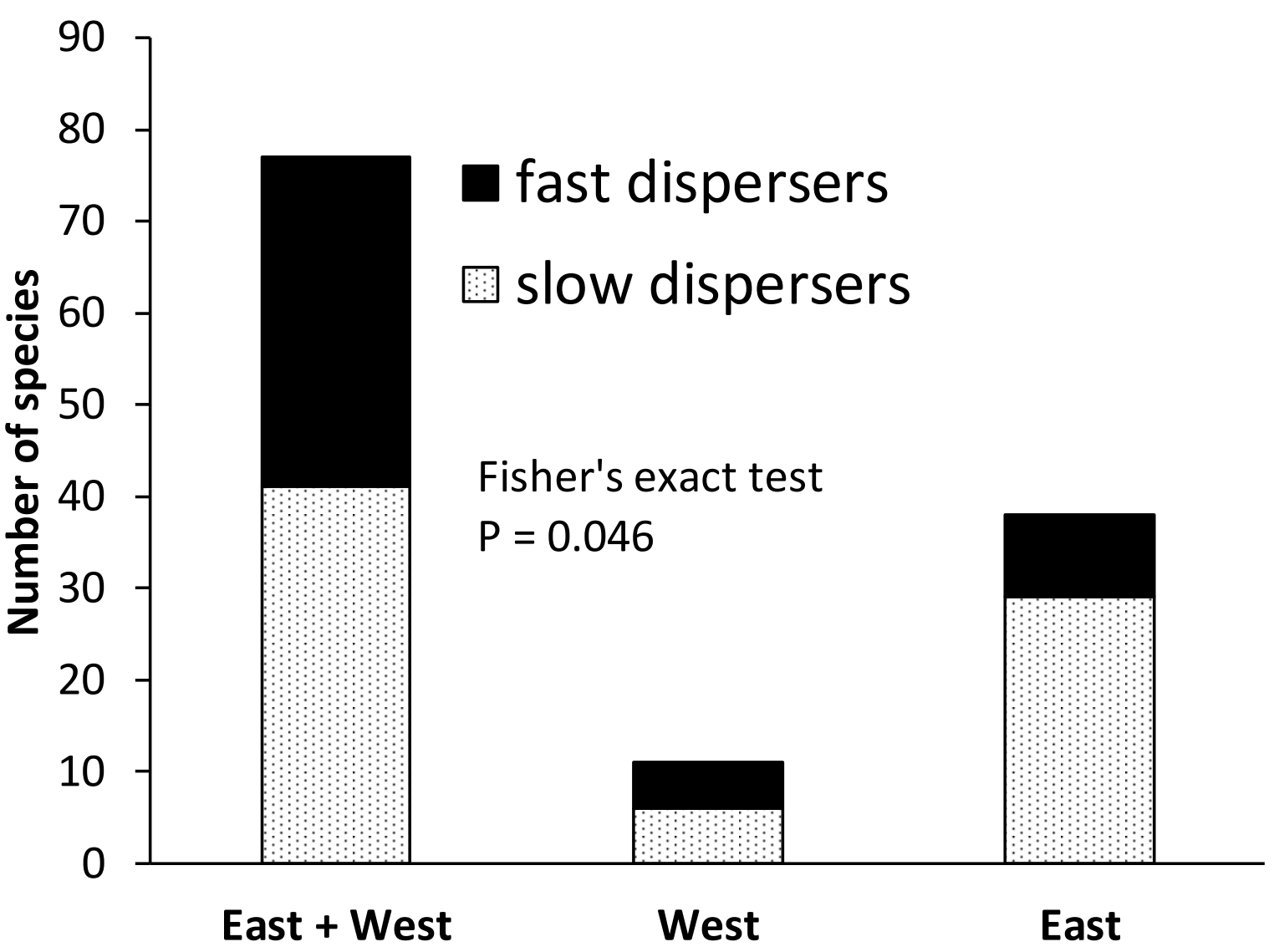

2 Fig. 4 


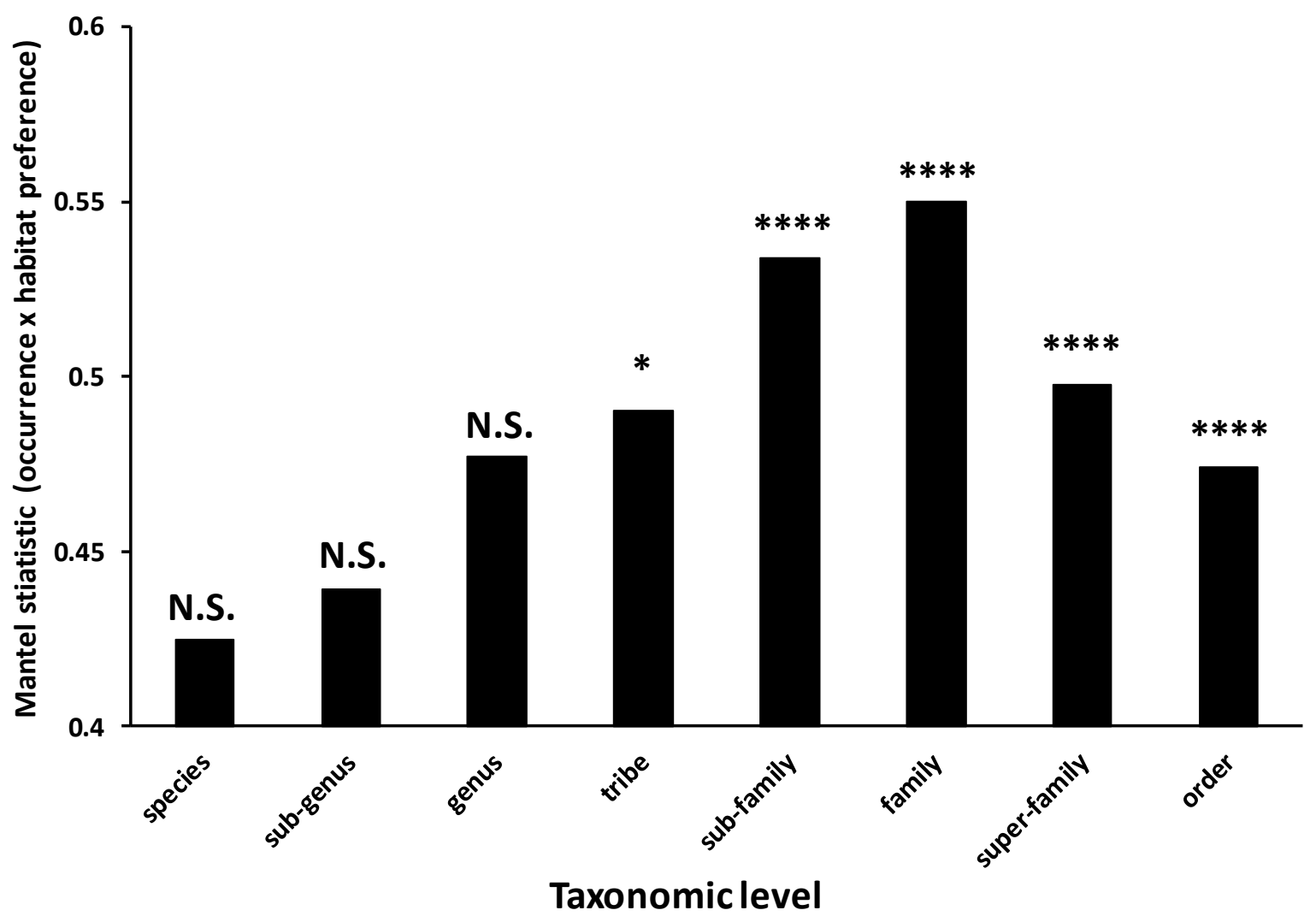

1

2 Fig. 5 


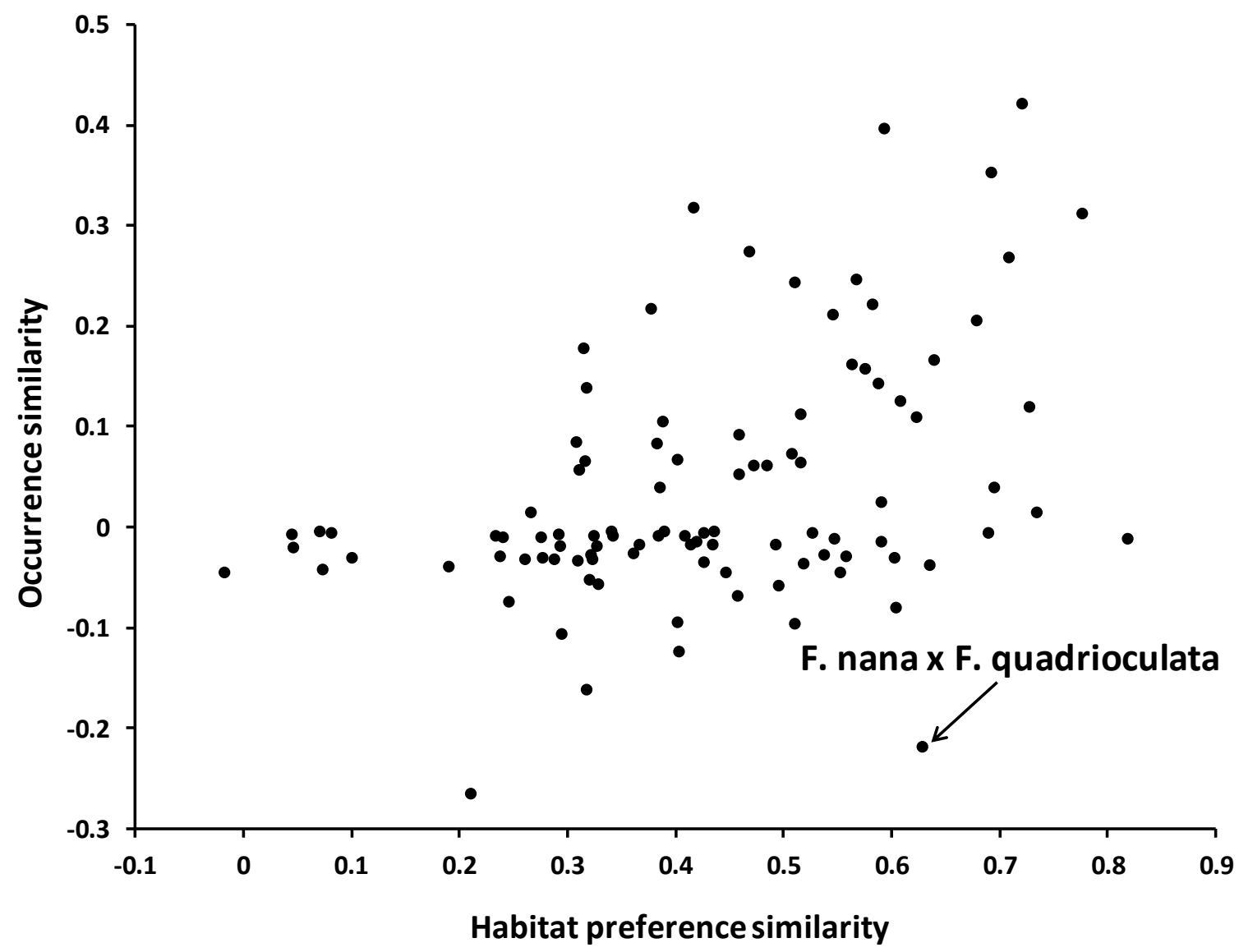

2 Fig. 6 
Appendix 1. Codes and species names of springtails collected in the Senart forest from 1973 to 1977, total number of specimens (abundance) and number of samples where the species was found (frequency)

Latin name (original document) Valid name (Fauna Europaea 2011) Abundance Frequency Latin name (original document) Valid name (Fauna Europaea 2011) Abundance Frequency Order Poduromorpha Anurida brunsvigiens

Anurida sensillata

Bilobella grassei
Brachystomella parula

Ceratophysella bengtssoni

Ceratophysella denticulata

Friesea claviseta

Friesea mirabilis

Friesea truncata
Hypogastrura purpurescens

Mesaphorura betschi

Mesaphorura italica

Mesaphorura krausbaueri

Mesaphorura macrochaeta

Mesaphorura massoudi

Mesaphorura sylvatica

Mesaphorura yosii

Micranurida pygmaea

Neonaphorura duboscqi

Neonaphorura novemspina

Neotullbergia ramicuspis

Odontella lamellifera

Oligaphorura absoloni

Onychiurus cebennarius

Onychiurus circulans

Onychiurus jubilarius

Onychiurus minutus
Onychiurus pseudogranulosus

Onychiurus pseudogranulos

Podura aquatica
Protaphorura groupe armata $(2+2)$

Protaphorura groupe armata $(2+2)$

Protaphorura groupe burmeisteri

Pseudachorutes parulus

Pseudachorutella asigillata

Schaefferia sexoculata

Stenaphorura denisi

Stenaphorura quadrispina

Wankeliella pongei

Willemia anophthalma

Willemia buddenbrock

Willemia intermedia

Willowsia nigromacul

Xenylla brevisimil

Xenylla grisea
Xenylla schillei

Xenylla schillei

Xenylla xavieri

Order Entomobryom
Cyphoderus albinus

Cryptopygus exilis

Cryptopygus scapelliferus

Cryptopygus thermophil

Entomonya lanuginosa

Entomobrya lanuginosa

Entomobrya muscorum

Entomobrya musc

Entomobryoides purpurascens

Folsomia candida

Folsomia cand nana

Folsomides parus

Anurida ellipsoides

Micranurida sensillata

Monobella grassei

Brachystomella parula

Ceratophysella bengtssoni

Ceratophysella denticulat

Friesea claviseta

Friesea mirabilis

Hypogastrura purpurescens

Mypogastrura purpurescora betschi

Mesporura betschi

Mesaphorura krausbaue

Mesaphorura mausbaueri

Mesaphorura massoudi

Mesaphorura hylophila

Mesaphorura yosii

Micranurida pygmae

Neanura muscorum

Neonaphorura duboscqi

Neonaphorura novemspina

Neotullbergia ramicuspis

Superodontella lamelirera

Micraphorura absoloni

Deuteraphorura fimetaria

Onychiurus ambulans

Detriturus jubilarius

Micronychiurus minutus

Onychiuroides pseudogranulosus

Paratullbergia callipygos

Podura aquatica

Promarantiaca

Kataphura subuliginat

Kalaphorura burmeister

Pseudachorute parulus

Schaefferia sexoculata

Stenaphorurella denisi

Stenaphorurella quadrispina

Wankeliella pongei

Willemia anophthalma

Willemia buddenbrock

Willemia intermedia

Willowsia nigromaculat

Xenylla brevisimilis

Xenylla grisea

Xenylla schillei

Xenylla tullberg

Xenylla xavieri

Cyphoderus albinus

Cryptopygus exilis

Cryptopygus scapelliferus

Cyplopys themos

(n)

Entomobrya multifasciata

Entomobrya muscorum

Entomobrya muscor

Entomobryoides purpurascens

Folsomia candida

Folsomia manolache

Folsomides parulus

Folsomides pusillus
Folsomia quadrioculata

Folsomia quadrioculata Order Entomobryomorpha (continued)

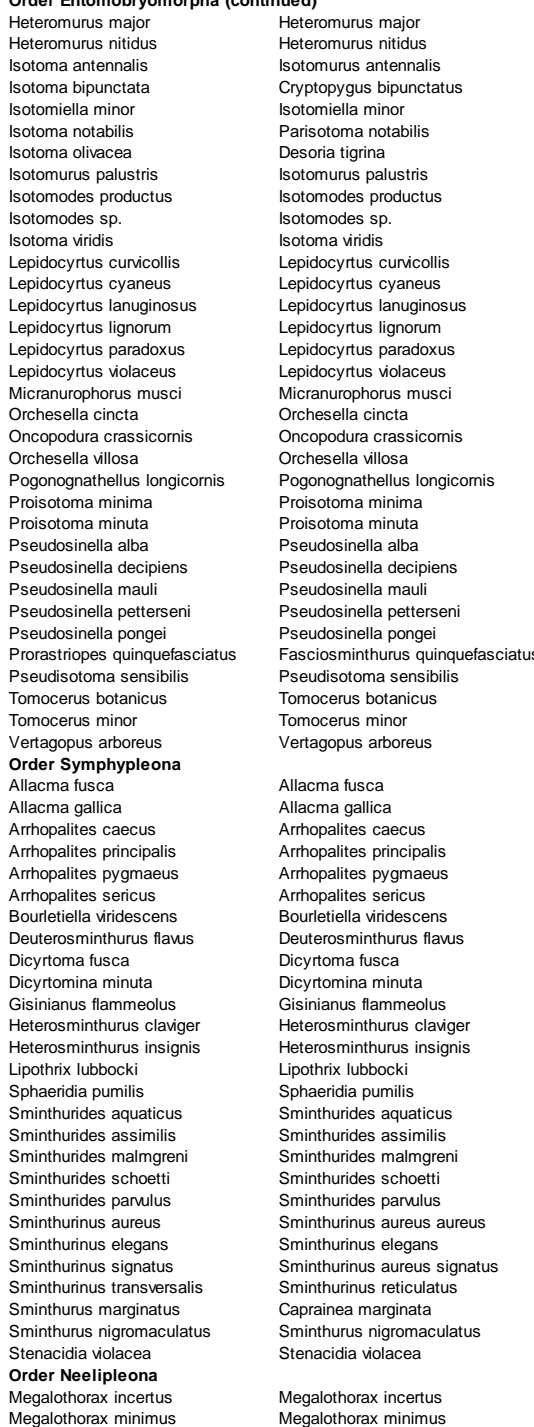

\begin{tabular}{|c|c|}
\hline 594 & 71 \\
\hline 28 & 18 \\
\hline 1 & 1 \\
\hline 2 & 1 \\
\hline 2136 & 116 \\
\hline 6095 & 180 \\
\hline 1192 & 5 \\
\hline 1483 & 101 \\
\hline 4 & 1 \\
\hline 2 & 2 \\
\hline 54 & 13 \\
\hline 72 & 26 \\
\hline 889 & 35 \\
\hline 3399 & 160 \\
\hline 565 & 63 \\
\hline 2 & 2 \\
\hline 4 & 4 \\
\hline 5 & 1 \\
\hline 1460 & 81 \\
\hline 5 & 3 \\
\hline 167 & 44 \\
\hline 7 & 5 \\
\hline 156 & 25 \\
\hline 212 & 10 \\
\hline 279 & 51 \\
\hline 7 & 6 \\
\hline 430 & 48 \\
\hline 1 & 1 \\
\hline 12 & 4 \\
\hline 2 & 2 \\
\hline 1464 & 12 \\
\hline 35 & 9 \\
\hline 312 & 45 \\
\hline 788 & 31 \\
\hline 1 & 1 \\
\hline 5 & 2 \\
\hline 23 & 6 \\
\hline 9 & 7 \\
\hline 13 & 7 \\
\hline 24 & 8 \\
\hline 50 & 15 \\
\hline 7 & 5 \\
\hline 34 & 19 \\
\hline 56 & 30 \\
\hline 98 & 6 \\
\hline 3 & 1 \\
\hline 33 & 7 \\
\hline 15 & 6 \\
\hline 1566 & 107 \\
\hline 1 & 1 \\
\hline 78 & 12 \\
\hline 591 & 43 \\
\hline 401 & 44 \\
\hline 82 & 13 \\
\hline 1054 & 75 \\
\hline 95 & 21 \\
\hline 2407 & 97 \\
\hline 1 & 1 \\
\hline 9 & 2 \\
\hline 16 & 9 \\
\hline 6 & 2 \\
\hline 12 & 9 \\
\hline 963 & 105 \\
\hline
\end{tabular}


Appendix 2. Environmental (habitat) indicators and total number of samples where indicators were quoted as 1 (frequency)

\begin{tabular}{lclc}
\hline & Frequency & & Frequency \\
\hline Autumn & 96 & Hornbeam & 42 \\
Winter & 108 & Linden & 22 \\
Spring & 88 & Maple & 8 \\
Summer & 46 & Ash & 8 \\
Grassland & 50 & Cherry & 9 \\
Woodland & 279 & Elm & 3 \\
Heathland & 9 & Elder & 3 \\
Ditch/brook & 44 & Hazel & 11 \\
Pond & 64 & Pine & 12 \\
Plain ground & 230 & Calluna & 6 \\
Water & 107 & Blackberry & 5 \\
Sunlight & 141 & Iyy & 4 \\
pH < 5 & 32 & Peat moss & 18 \\
pH 5-6 & 35 & Hair moss & 5 \\
pH > & 32 & Feathermoss & 8 \\
Limestone & 48 & Liverwort & 1 \\
Sand & 20 & Lichens & 4 \\
Pebbles & 23 & Algae & 3 \\
Mull & 57 & Bracken & 21 \\
Moder & 24 & Purple moor grass & 21 \\
Mor & 2 & Hair-grass & 5 \\
Hydromull & 6 & Fescue-like grass & 8 \\
Hydromoder & 3 & Rushes & 6 \\
Hydromor & 3 & Waterlilies & 10 \\
Trunk & 33 & Hawksbeard & 1 \\
Herbs (aerial parts) & 58 & Sedges & 4 \\
Mosses (aerial parts) & 74 & Wood anemone & 20 \\
Superficial soil & 17 & Bluebell & 20 \\
Litter & 80 & Duckweed & 1 \\
Humus & 41 & Mustard & 1 \\
Organo-mineral soil & 18 & Chamomile & 1 \\
Mineral soil & 68 & Chickweed & 9 \\
Mole hill & 4 & Yarrow & 4 \\
Vertebrate dung & 3 & Nettle & 5 \\
Garbage deposits & 11 & Mercury & 16 \\
Wood & 35 & Solomon's seal & 8 \\
Earthworm casts & 7 & Wheat & 7 \\
Tree roots & 5 & Buttercup & 1 \\
Herb roots & Knotweed & 1 \\
Oak & Mint & 5 \\
Birch & & & 1 \\
\hline
\end{tabular}


Appendix 3. Traits and trait attributes used to describe the 127 springtail species of the Sénart forest

\begin{tabular}{ll}
\hline Traits & Attributes \\
\hline Reproduction type & Parthenogenesis dominant \\
Body length & Sexual reproduction dominant \\
& Small $(<2 \mathrm{~mm})$ \\
& Medium $($ between 2 and $3 \mathrm{~mm})$ \\
& Large $(>3 \mathrm{~mm})$ \\
Body shape & Slender body \\
& Stocky body \\
& Spheric body \\
Body color & Pale-colored body \\
& Bright-colored body \\
Presence of scales & Dark-colored body \\
& Scales absent \\
Antennal length & Scales present \\
& Short antennae \\
Leg length & Long antennae \\
& Short legs (leg/thorax+abdomen $<0.3)$ \\
Furcula length & Long legs (leg/thorax+abdomen $\geq 0.3)$ \\
& Furcula absent or vestigial \\
Eye number & Short furcula (anterior part of Abd II not reached) \\
& Long furcula (anterior part of Abd II reached) \\
Presence of pseudocella & Ocella absent \\
Presence and complexity of the post-antennal organ & Ocella 1-5 \\
Presence of trichobothria & Ocella $>5$ \\
& Pseudocella absent \\
& Pseudocella present \\
& Post-antennal organ absent \\
& Post-antennal organ simple \\
& Post-antennal organ compound \\
& Trichobothria absent \\
& Trichobothria present \\
\hline
\end{tabular}

